\title{
tDCS targeting the Ventromedial Prefrontal Cortex reduces reactive aggression and modulates electrophysiological responses: A HD-tDCS/EEG randomized controlled trial in a forensic population.
}

Carmen S. Sergiou ${ }^{1}$, Emiliano Santarnecchi ${ }^{2}$, Sara M. Romanella ${ }^{2}$, Matthias J. Wieser ${ }^{1}$, Ingmar H.A. Franken ${ }^{1}$, Eric G.C Rassin ${ }^{1}$, Josanne D.M. van Dongen ${ }^{* 1}$

\footnotetext{
${ }^{1}$ Department of Psychology, Education and Child Studies, Erasmus University Rotterdam, Rotterdam, the Netherlands.

${ }^{2}$ Berenson-Allen Center for Non-Invasive Brain Stimulation, Beth Israel Medical Center, Harvard Medical School, Boston, MA, USA.
}

${ }^{*}$ Correspondence should be addressed to:

Carmen Sergiou or Josanne van Dongen, Ph.D.

Erasmus University Rotterdam

Department of Psychology, Education and Child Studies

P.O. Box 17383000 DR Rotterdam

sergiou@essb.eur.nl

j.d.m.vandongen@essb.eur.nl 


\section{ABSTRACT}

Background Studies have shown that impairments in the ventromedial prefrontal cortex (vmPFC) in forensic patients who also abuse cocaine and alcohol, play a crucial role in violent behavior. Moreover, interventions that aimed to reduce violence risk in those patients are found not to be optimal. A promising intervention might be to modulate the vmPFC by high-definition (HD) transcranial Direct Current Stimulation (tDCS). The current study aimed to examine (HD)-tDCS as an intervention to increase empathic abilities and reduce violent behavior in forensic substance dependent offenders. In addition, using electroencephalography (EEG), we examined the effects on the P3 and the Late Positive Potential (LPP) of the Event-Related Potentials (ERPs) in reaction to situations that depict victims of aggression.

Methods: Fifty male forensic patients with a substance dependence were tested in a double-blind sham-controlled randomized study. The patients received HD-tDCS two times a day for $20 \mathrm{~min}$ for five consecutive days. Before and after the intervention, the patients completed self-reports, performed the Point Subtraction Aggression Paradigm (PSAP), and EEG was recorded while patients performed an empathy task.

Results: Results showed a decrease in aggressive responses on the PSAP and in self-reported reactive aggression in the active tDCS group. Additionally, we found a general increase in LPP amplitude after active tDCS. No effects on trait empathy and the P3 were found.

Conclusion: Current findings are the first to find positive effects of HD-tDCS reducing aggression and modulate electrophysiological responses in forensic patients, showing the potential of using tDCS as an intervention to reduce aggression in forensic mental healthcare.

This study was preregistered at the Dutch Trial Register, NTR7701. https://www.trialregister.nl/trial/7459

Keywords: Empathy, aggression, forensic patients, neuromodulation, transcranial direct current stimulation, electroencephalography 


\section{Introduction}

Substance abuse is a major concern in forensic patients and poses a major risk for violence in these individuals [1]. Substance use offenders are found to have increased odds of violent behavior [2-9]. Moreover, repeatedly using substances has been found to be associated with functional neuroadaptations in the prefrontal cortex (PFC) [2, 3]. Especially the Ventromedial Prefrontal Cortex (vmPFC) is found to be associated with substance use disorders (SUD) in regulating reward processing and motivational salience $[3,10-15]$. Recent studies $[6,7]$ show that the vmPFC is also involved in antisocial behavior, especially aggression $[16,17]$ and impulsivity, in abusers of alcohol and cocaine [18-24]. The vmPFC is found to be crucial for regulating emotions [25-37] and has a specific role in Theory of Mind (ToM)- processes $[31,32]$ that are vital in empathic processing due to cognitively adopting the other's perspective [38].

In addition, neuroimaging studies showed that the structures that are relevant for empathy and the modulation of aggressive behavior, namely the vmPFC and medial frontal regions, [7, 39-49] are impaired in individuals with antisocial traits [50-54]. One study [55] used the Point Subtraction Aggression Paradigm (PSAP; [56]) and also indicated a link between brain activity in the vmPFC and aggressive behavior, proposing the vmPFC to be a neural substrate related to aggressive provocation [55]. Other studies [57-62] demonstrated that the vmPFC is related to increasing costs and retaliation of the aggressor and greater punishment choices.

Following the proposed neurocognitive models of Blair $[39,42,63]$, violence is inhibited by empathy, and therefore individuals with deficits in their empathic abilities are less susceptible and less motivated to inhibit aggression, which increases the risk of violent behavior [64].

Whereas the association between the PFC and aggression has been studied in different 
neuroimaging, behavioral and clinical studies, to our knowledge little is known about the causal role of the vmPFC in empathic abilities and violent behavior in forensic patients. Therefore, modulating the $\mathrm{vmPFC}$ to increase empathic abilities and reduce violent behavior in these patients could be of substantial importance for supporting a causal relation and for formulating new treatment interventions.

A promising tool to modulate empathic abilities and aggression is transcranial Direct Current Stimulation (tDCS). In the review paper of Sergiou et al. [65] multiple studies were reviewed that used tDCS to modulate aggression [66-68] or empathic abilities [41, 69-71], and concluded that the vmPFC would be the most promising target area for modulating these behaviors. tDCS is a neuromodulation technique that uses electrical currents to increase or decrease activity in the brain region of interest and has been proven effective in many disorders [72-74]. tDCS uses a sub threshold modulation of the membrane potentials of neurons through altering cortical excitability $[75,76]$ and can change synaptic neuronal plasticity [74]. This change in neuronal plasticity is found to produce Long Term Potentiation (LTP)-like 'learning' in the modulated neurons $[78,79]$. In this rapidly evolving field, studies have shown that the stimulation effect is based on the strength, duration of the current and polarity-dependent changes [81-83] and that the results of modulation could be changed due to the nature of previous brain activity as described by the Bienenstock-Cooper-Munroe rule (BCM [84]) [85-89].

To date, the majority of the studies that investigate the modulation of the PFC have relied on conventional tDCS, upregulating one side of the brain and downregulating the contralateral region [80]. An even more promising tDCS technique is High-Definition tDCS (HD-tDCS), which uses multiple compact (i.e. $<5 \mathrm{~cm}^{2}$ ) circular electrodes to deliver the low current [90] and studies have shown that HD-tDCS can target brain structures with higher focality [91]. In this way, deeper regions of the brain, such as the vmPFC, can be modulated 
in an optimal way [92-98]. Therefore, in the present study we will use a protocol using HDtDCS targeting the vmPFC, with multiple sessions and with enhancing the brain state during modulation to maximize the effect [99-102].

To study the effect of tDCS on brain functioning, the temporal dynamics could be studied using electroencephalography (EEG; [103-105]). The event-related potential (ERP) technique has mostly been used to investigate empathy, by measuring brain responses to pictures. Studies have shown that both early and late ERP components are related to perceived pain in others $[103,106,107]$ and in reaction to self-reported trait empathy $[105$, 108-110]. Two ERPs that have been studied extensively are the P3, and late positive potential (LPP).

The P3 is an ERP that has a positive voltage in the latency of 300-650 milliseconds (ms; [111]). The P3 is typically associated with controlling sustained attention towards salient stimuli [111] and has been linked to empathy for pain [103,106, 112-116]. The LPP is a positively sustained ERP that occurs around $400-1000 \mathrm{~ms}$ and is located at the parietal locations and the central midline [117] and is associated with empathy and emotional cues. A study of Cuthbert et al. [112] demonstrated that the LPP indicates an increase in amplitude towards emotional stimuli, arousal, regulation, facial expressions, and affective experience regulation and the study of van Dongen et al., [105] found reduced P3 and LPP in individuals with decreased empathic abilities. Therefore, studying these positive potentials contribute to the understanding of emotional regulation $[103,112,118,119]$, and serve as an indication that the temporal dynamics of empathic processing in the brain can be studied using late ERPs in the EEG.

The main aim of the current study was to examine whether modulating activity in the vmPFC using HD-tDCS would increase empathic abilities and reduce aggressive behavior in forensic substance dependent patients. In addition, in this study we investigated the effects of 
the HD-tDCS intervention on electrophysiological responses (P3 and LPP) to situations that depict victims of aggression (i.e. empathy). Based on prior literature, it was expected that following active tDCS, compared to sham, empathic abilities would increase and aggression would decrease. Additionally, it was expected that the P3 and LPP amplitude following the viewing of pictures that depict victims of aggression, would be increased after active tDCS compared to sham tDCS.

Knowledge gained from the current study will give insight in the casual relation between activity in the vmPFC, empathy and aggression and can inform in the development of new neuromodulation (e.g. tDCS) protocols for treatment interventions in violent forensic populations.

\section{Materials and Methods}

\section{Participants}

Fifty male participants (mean age $=37.40$ years, $S D=9.19$ years, range: $22-62$ years) were recruited from two departments of the division for forensic addiction mental healthcare of Antes in Poortugaal, the Netherlands, between February and October 2019. Twenty-one participants were recruited at the Forensic Addiction Clinic (FVK) and 29 from the Department of Forensic Care (AFZ). The patients were randomly assigned to either one of the conditions and participated in a double-blind placebo-controlled study with two conditions. Twenty-five participants received treatment as usual (TAU) + active stimulation, and 25 participants received treatment as usual (TAU) + sham (placebo). For an overview of the demographic characteristics of the sample see Table 1. Inclusion and exclusion criteria are presented in the Supplement S1.

The participant flow and recruitment according to the Consolidated Standards of Reporting Trials (CONSORT) can be found in the Supplement S2. 


\section{Procedure and design}

The study consisted of a double-blind, placebo-controlled, randomized trial comparing a group that received active HD-tDCS intervention with a sham control group. Baseline assessments including self-report questionnaires, a resting-state EEG task, passive viewing task [105], rating empathy task [105] and the Point Subtraction Aggression Paradigm (PSAP; [56]) were conducted during the pre-intervention. During the following week, the participants received 2 times 20 minutes HD-tDCS stimulation or sham intervention targeting the vmPFC for five consecutive days (see the Supplement S3 for a flowchart of the procedure). There was approximately 3-4 hours between the two sessions, depending on the patients schedule and TAU. Outcome measurements were conducted one week later during the post-intervention. Self-report questionnaires and tasks were conducted in a fixed order.

A study by Nissim and colleagues [120] using fMRI demonstrated that the optimal gains from using tDCS could be realized by increasing the activity of the brain area of interest (i.e. the brain state). Therefore, to optimize our intervention, we increased the activity of the vmPFC while stimulating, by showing the patients two empathic movies $[121,122]$ and the Reading the Mind in the Eyes task (RMET; [123]) to trigger these brain states. Patients and investigators were blind to the tDCS allocation. The principal investigator of the project, who was not involved in data collection and initial statistical analysis, preprogrammed the tDCS device in active condition or sham condition matched with a number.

The study was conducted in accordance with the ethical standard of the Declaration of Helsinki [124] and is approved by Medical and Ethical Review Board of the Erasmus Medical Centre Rotterdam. The trial protocol was registered at the Dutch Trial Register, (NTR7701). See also Sergiou et al. [125] for the complete published study protocol.

\section{High-Definition tDCS intervention}

HD-tDCS was administered with the CE-certified Neuroelectrics Starstim $8^{\circledR}[126]$, 
operating according to the evidence-based guidelines of LeFaucheur et al. [127]. Before commencement of the study, the HD-tDCS montage optimization was based on the currentflow modeling of the NIC-software of the tDCS Starstim $8^{\circledR}$ system [126], (see the protocol [125] for detailed description). In addition, the induced E-field of the HD-tDCS montage was computed in SimNibs v3.2 [128]. Detailed description on biophysical modeling can be found in the Supplement S5

The currents were transmitted through six circular Ag/AgCl PiStim "High Definition" electrodes $\left(1 \mathrm{~cm}\right.$ radius, $\left.\pi \mathrm{cm}^{2}\right)$ that were applied with conductive gel. The resulting Norm-E field and Normal E-field distribution is created in Gmsh v4.7.1. [129] with an output range from 0 to $0.25 \mathrm{~V} / \mathrm{m}$ (see Figure 1). The HD-tDCS device was programmed for stimulation with $2 \mathrm{~mA}$ tDCS during 20 minutes for modulating the vmPFC of the participants in the active condition. The sham condition followed the exact same procedure, with a 30 seconds ramping-up and down the tDCS currents at the beginning and end of the protocol, based on earlier research indicating this method being effective for blinding [130]. The anodal electrode was placed on the Fpz location, and the five return or cathodal electrodes were placed on AF3, AF4, F3, Fz and F4 (see Figure 1 for the electrical field model) and the Supplement S5 for detailed description of the biophysical modeling).

\section{Electrophysiological measurement empathy}

To assess EEG measuring empathy, the patients had to perform a Passive Viewing Empathy task [105]. This task was designed to measure empathic abilities through EEG. This task consists of 95 pictures displaying scenes for $6000 \mathrm{~ms}$ with either an aggressive interaction (45), a neutral interaction (45) or a neutral object (i.e. fillers; 45). The aggressive pictures consisted of either a sexual, verbal or physical interaction. Participants were instructed to view all the pictures passively; in this way the automatic neural responding in the brain could be determined in a most optimal way [105]. 


\section{State empathy}

To assess state empathy, the patients had to perform a Rating Empathy Task [105]. Following the Passive Viewing Empathy task, the 95 pictures were presented another time to the patients. In this task they were instructed to rate the pictures by answering four questions regarding arousal, emotional valence, empathy for victim and perpetrator.

\section{Aggression task}

To assess aggression, we used the Point Subtraction Aggression Paradigm (PSAP; [56]). The PSAP is one of the best-validated paradigms to measure aggression in a lab environment [131].

A detailed description of the tasks used in this study included in the Supplement S2.

\section{Self-report questionnaires}

For a complete overview of the self-report questionnaires used in the overall study see Sergiou et al., [125]. The questionnaires used in the analysis of this paper mentioned below and described in more detail in the Supplement S2.

Reactive and Proactive Aggression Questionnaire (RPQ; [132]). In order to assess trait aggression, we used the Dutch translation of the RPQ [133].

Interpersonal Reactivity Index (IRI; [134]) In order to assess trait empathy, we used the Dutch translation of the IRI [135], this is a commonly used self-report instrument designed to assess empathic tendencies.

The Alcohol Use Disorders Identification Test (AUDIT [136]. In order to assess alcohol use, we used the Dutch translation of the AUDIT [137]. The 10-item AUDIT includes questions to assess alcohol, intake, alcohol dependence and alcohol-related problems.

The Drug Use Disorders Identification Test (DUDIT; [138]. In order to assess drug use, we used the Dutch translation of the DUDIT [139]. The DUDIT is an 11-item screening instrument to assess non-alcohol drug use patterns and various drug-related problems. 


\section{EEG recording}

EEG was recorded using a mobile version of the BrainProducts [140] Active-Two System amplifier (Amsterdam, the Netherlands). Thirty-two electrodes were placed on the scalp of each participant following the international 10-20 EEG-system. Two other additional electrodes were placed vertically above and beneath the left eye (electro-oculogram; EOG), the electrodes for the left and right mastoid placement were incorporated in the EEG cap. The EEG and EOG signals were digitized with a sampling rate of $500 \mathrm{Hertz}(\mathrm{Hz})$ and 24-bit analog-to-digital conversion with offline filtering.

\section{EEG data preprocessing}

Data were preprocessed offline using Brain Vision Analyzer [141]. Segmentation was done per condition (neutral vs. aggression) for both P3 and LPP at pretest and posttest, in an interval of $1200 \mathrm{~ms}(-200 \mathrm{~ms}$ to $1000 \mathrm{~ms}$; see van Dongen et al., [105]) relative to stimulus presentation. Next, the data was filtered using a bandpass filter ranging from $.01 \mathrm{~Hz}$ to $30 \mathrm{~Hz}$ (phase shift-free Butterworth filters; $24 \mathrm{~dB} /$ octave slope), the signal was corrected for ocular artifacts using the Gratton and Coles algorithm [142], trials with remaining artifacts (i.e., segments with an EEG signal exceeding an amplitude of $100 \mu \mathrm{V}$ ) were excluded from further analysis [105], and data was baseline-corrected (200 ms pre-response or pre-stimulus period served as baseline). Nine participants had to be removed from the analyses due to excessive amounts of artifacts in the data (i.e., less than 15 artifact-free segments). Bad channels with too many artifacts were corrected with topographic interpolation. This resulted in a set of EEG data of 41 participants, 21 in the sham condition and 20 in the active tDCS condition.

Because the highest amplitude of P3 and LPP typically is seen at Pz [143,144], inspection of the grand average ERPs (see Figure 3) demonstrated a maximal amplitude for aggressive pictures around 400ms after stimulus onset (P3) and followed by the slow wave activity of the LPP, which returned to baseline after $6000 \mathrm{~ms}$. For analyzing the ERPs, the P3 
amplitude was defined as the mean amplitude of the Pz between $350 \mathrm{~ms}$ and $450 \mathrm{~ms}$ after stimulus onset $[105,106]$. The LPP was analyzed at the mean amplitude of the Pz between 500 and $1000 \mathrm{~ms}$ after stimulus onset $[105,145]$. The average signal per condition was then used for determining the characteristics of the ERP.

\section{Statistical analyses}

Self-report and the electrophysiological outcomes were analyzed using SPSS 25 [146]. To test the differences between the active and the sham group from pre- to posttest on the state empathy following the aggression versus the neutral condition, four 2 (Time; pre vs. post) $\mathrm{x} 2$ (Group; active tDCS vs. sham) ANOVAs were conducted for the scoring on arousal, emotional valence, victim and perpetrator. Similarly, to test the differences between the active and the sham group from pre to posttest on state aggression (PSAP), a repeated measures ANOVA was performed. Aggression was indicated by the proportion of aggressive responses. Thus, the number 2 presses divided by the total amount of presses (i.e., [No. option 2]/[No. of total button presses])

To investigate the electrophysiological outcomes of the P3 and LPP, two 2 (Time; pre vs. post) x 2 (Emotion; aggressive vs. neutral) x 2 (Group; active tDCS vs. sham) repeated measures ANOVAs were conducted. For all statistical tests, the level of signifance was set at $p<.05$.

\section{Results}

The result from the HD-tDCS simulation (Figure 1B) demonstrates that the vmPFC was reached with intensity sufficient to induce effect of the stimulation $(0.11-0.2 \mathrm{~V} / \mathrm{m}$ (see the Supplement S5 for details).

See the Supplement S6 for a report on adverse effects. Descriptive statistics for all the measures used in this study, including all the self-report questionnaires, can be found in Table 2. Results showed no significant difference between medication use and the two conditions 
$(\mathrm{tDCS}$ and sham $), \mathrm{X}^{2}(3, \mathrm{~N}=50)=3.1, p=.378($ see the Supplement $\mathrm{S} 8)$.

\section{State empathy outcomes}

Concerning state empathy there were no significant main effects for arousal, emotional valence, empathy for victim or empathy for perpetrator between the tDCS group and the sham group from pre-posttest. Furthermore, we did not find any significant interaction effects.

\section{Aggression outcomes}

Regarding the PSAP task there were no significant main effects for Time or Group. We did find a significant Time x Group interaction effect (see Figure 3), with $F_{(1,48)}=5.87, p$ $<.019, \eta_{p}{ }^{2}=.11$. Post-hoc tests revealed that the effect is significant $(p=.027)$ for the tDCS group and not significant for the sham group $(p=.192)$. These results imply that the decrease in aggression from pre to post test was significantly stronger in the tDCS group than in the control group, with a moderate to large effect [147].

\section{Self-report questionnaires}

Regarding the RPQ we found a significant effect of Time on the RPQ total score $\left.F_{(1,47)}=9,51, p=.003, \eta_{p}^{2}=.25\right)$ and RPQ reactive aggression subscale $\left(F_{(1,48)}=10.68, p=\right.$ $\left..002, \eta_{\mathrm{p}}{ }^{2}=.19\right)$ over the two groups. There were no main effects of Group. These results indicate a significant reduction in self-reported reactive aggression after the intervention as compared to the pretest across both groups. There were no significant findings for the SRPSF, IRI, AUDIT or DUDIT.

\section{P3 and LPP}

See Figure 3 for an overview of the grand average of P3 and LPP in the active tDCS and sham group from pre- to posttest.

Analyses of the P3 amplitude showed no significant main effect for Time, Group or 
Emotion. The results indicated a significant interaction effect between Time and $\operatorname{Group}\left(F_{(1,39)}\right.$ $\left.=4.52, p=.040, \eta_{p}^{2}=.10\right)$, but not for Emotion. Follow-up $t$-tests revealed that the sham group showed a significant $[t(20)=3.07, p<.01]$ decrease in P3 amplitude from pre- $(M=$ 3.07, $S D=3.82)$ to posttest $(M=1.47, S D=4.76)$. Graphs are displayed in Figure 4.

Analyses of the LPP amplitude resulted in a significant main effect for Emotion $\left(F_{(1,39)}\right.$ $=5.62, p=.023, \eta_{p}^{2}=.13$ ), meaning that aggression pictures led to higher LPP amplitudes compared to the neutral pictures in both groups. There were no main effects for Time or Group. In addition, we found a significant interaction effect between Time $\mathrm{x}$ Group $\left(F_{(1,39)}=\right.$ 5.66, $\left.p=.022, \eta_{p}^{2}=.009\right)$. Follow-up $t$-tests revealed that the tDCS group showed a significant $[t(19)=-2.29, p=.03]$ increase in LPP amplitude compared to the sham group, from pre to posttest, independent of emotion. Meaning an overall increase in amplitude after the intervention for the tDCS group. Graphs are displayed in Figure 5.

To check if the increase in LPP amplitude from pre- to post-test for both aggression and neutral pictures was also present in the filler pictures an additional analysis was performed (see the Supplement S4). Results showed no significant effects on Time, Group or Emotion.

\section{Discussion}

The aim of this study was twofold. First, we examined HD-tDCS as an intervention to increase empathic abilities and reduce violent behavior in forensic patients with a substance dependence. Second, we examined the HD-tDCS effects on the electrophysiological responses (P3 and LPP) to situations depicting victims of aggression. Since the intervention was the tDCS treatment in addition to TAU, all the found effects are a product of the interaction between the intervention (or placebo) and the TAU. 
Results showed no effects of tDCS on state empathy. Although this is not what we had expected, it can be explained by the fact that the vmPFC may not be directly related to empathic abilities. As shown in the model of Blair [63], decreased activity in the vmPFC is linked to impaired social and affective decision making, and the vmPFC is found to be involved in perspective-taking and regulating emotions [103-105], that are vital for empathic processing [31], but not related to empathy directly.

Consistent with our hypothesis, we found a reduction in reactive aggression on the aggression task from pre-to posttest in the active tDCS group compared to the sham group. Additionally, we found the same effect for self-reported reactive aggression and the total aggression score as measured with the RPQ. The reduction of reactive state and trait aggression are consistent with previous findings on the associating between the vmPFC and aggressive behavior [17-24]. Previous research also indicated a link between the brain activity in the vmPFC and the aggressive behavior measured with the PSAP, proposing the VmPFC to be a neural substrate related to aggressive provocation [55, 57-62]. Consistent with these results is the proposed framework of Blair [64], which demonstrates that diminished activity in the vmPFC leads to frustration-based reactive aggression. Consequently, the present study provides insight into the functional role of the vmPFC in reactive aggression and how modulating activity in the vmPFC can reduce aggressive responses in the laboratory setting. Future research has to show the generalizability of these results to violent behavior outside the laboratory.

With respect to the electrophysiological measures (P3 and LPP), we expected that after a week of tDCS intervention, aggressive pictures would result in larger ERP amplitudes (more arousal, more empathy) compared to neutral pictures. This hypothesis was partly confirmed. Regarding the P3, only an interaction effect was found between Time and Group, showing that the P3 amplitude decreased from pre- to post-test in the sham group. One of the 
reasons could be that the inhibitory effect was caused by a learning effect. Studies [148-150] have shown that the P3 is very sensitive for learning effects in repeated measure design, and that the amplitude becomes smaller when target probability increases [151-157].

Results for the LPP showed an increase in amplitude for the active tDCS group in both emotion conditions, although active tDCS did increase LPP amplitudes as expected, we did not expect that the LPP amplitude would also increase for neutral pictures. An explanation for this finding would be that modulating activity in the vmPFC resulted in a modulation effect in social interactions generally, regardless of the emotions displayed in the pictures. To test this hypothesis, we performed an additional analysis on the filler pictures (i.e. neutral objects) and indeed found no significant effects of tDCS on either the P3 or LPP following viewing filler pictures. Thus, even though the results did not differentiate between neutral or aggressive pictures as proposed, the current results are in line with previous research $[83,98,145,147$ 149] indicating that the positive slow potentials indicate an increased emotional regulation and affective experience (see the supplementary materials (S7) for detailed description of the additional analysis).

Our model of current flow indicated that the HD-tDCS stimulation reached the vmPFC with intensity sufficient to induce an effect of the stimulation as also described in earlier studies [158-160]. We do acknowledge that a factor of inter-individual variability should also be taking in consideration. Future studies could implement specific algorithms or potential biophysical modeling to individualize montage and take into account the potentially influencing factors contributing to the direction of current flow [161-165]. This paper has several strengths. First, this study is the first to find a decrease in aggression in forensic patients using an EEG-tDCS design. Other studies $[75,166,167]$ that have shown reduced aggression with tDCS did not include EEG in their protocol, although of significant importance for monitoring the activity of the brain region of interest. Second, we used a 
design that was double blind and with multiple sessions of tDCS. It has been demonstrated in several studies [168-175], that modulation is most effective after multiple sessions, because the induction of synaptic plasticity in the cortex requires a multiple time stimulation to be effective and to mediate the durability of neocortical circuits [176]. Third, in the current study the current flow montage sufficiently reached the vmPFC. We used HD-tDCS which is found to have a better focality $[176,177]$ than conventional tDCS, and as a result reaches deeper regions of the brain [92-98]. Fourth, compared to previous studies [96,97] we optimized the intervention by enhancing the brain state of interest during the tDCS sessions [120].

Albeit promising, our findings should be interpreted in the context of limitations that are important to consider in future studies investigating this matter. First, we found a significant decrease in the P3 amplitude for the sham condition. Future studies should try to correct for learning effects on the P3 by implementing slightly different pictures in the viewing task or have a longer period from pre to posttest. Second, it might not just be the impairments of the PFC that influence aggression and antisocial behavior, but neural network disruptions associated with that behavior [i.e. 178]. Therefore, it would be relevant to investigate neural networks and functional connectivity in understanding aggressive behavior in future studies. Third, future studies should highlight the role of tDCS as a modulator, the effects of tDCS on synaptic activity as according to the BCM rule [84-89] and using potential biophysical modeling to individualize montage. Last, in this study, no long-term effects of the tDCS intervention were examined, nor effects on violence in real life. Future studies should address these issues to further support the effectiveness of this tDCS intervention.

\section{Conclusion}

The development of successful evidence-based therapeutic interventions in forensic mental health is crucial for reducing violence risk. To our knowledge this is the first study 
investigating HD-tDCS as an intervention to increase empathic abilities and reduce violent behavior in a forensic sample, and that also examined the effects on electrophysiology. Our results showed that multiple sessions of HD-tDCS targeting the vmPFC resulted in reduced aggression. In addition, this modulation also resulted in increased LPP amplitudes following aggressive pictures, indicating an increase in attention to, and emotional evaluation of scenes depicting victims of aggression. Hence, our results significantly improved our understanding of the neural correlates of aggression posed by violent individuals and although it has to be interpreted with caution when implicating in a real life setting, give support for the effectiveness of tDCS as treatment intervention in forensic patients.

\section{ACKNOWLEDGMENT AND DISCLOSURES}

A previous version of this article was published as a preprint on PsyArXiv Preprints: DOI: 10.31234/osf.io/cjgdt.

Drs. Sergiou received a grant from the Prins Bernhard Cultuurfonds and a grant from the ZonMw, both located in the Netherlands. Drs. Sergiou reported no biomedical financial interests or potential conflicts of interest. Dr. Santarnecchi is partially supported by Office of the Director of National Intelligence (ODNI), Intelligence Advanced Research Projects Activity (IARPA), via 2014-13121700007. The views and conclusions contained herein are those of the authors and should not be interpreted as necessarily representing the official policies or endorsements, either expressed or implied, of the ODNI, IARPA, or the U.S. Government. Dr. Santarnecchi is supported by the Beth Israel Deaconess Medical Center (BIDMC) via the Chief Academic Officer (CAO) Award 2017, the Defense Advanced Research Projects Agency (DARPA) via HR001117S0030, and the NIH (P01 AG03172006A1, R01 MH117063-01, R01 AG060981-01). The content of this paper is solely the 
responsibility of the authors and does not necessarily represent the official views of Harvard University and its affiliated academic health care centers, or the National Institutes of Health. Dr. Santarnecchi reported no biomedical financial interests or potential conflicts of interest. Drs. Romanella reported no biomedical financial interests or potential conflicts of interest. Prof Dr. Wieser reported no biomedical financial interests or potential conflicts of interest. Prof Dr. Rassin reported no biomedical financial interests or potential conflicts of interest. Prof Dr. Franken reported no biomedical financial interests or potential conflicts of interest. Dr. van Dongen was sponsored by the program "Kwaliteit Forensische Zorg" of the Expertise Center Forensic Psychiatry, Stiching Koningsheide and Stichting Volksbond Rotterdam in the Netherlands. Dr. van Dongen reported no biomedical financial interests or potential conflicts of interest.

We thank Nico van Beveren for the supervision of the project at the forensic clinics and the departments FVK and AFZ and staff for their cooperation. Furthermore, we thank Alix Weidema, Celine de Reus, Thijs Vlak, Jitse Holl, Rozemarijn Pons and Aylin Dasdemir for their contribution in collecting the data.

\section{Supplementary Material}

Supplementary Materials. 


\section{References}

[1] Pickard, H., \& Fazel, S. (2013). Substance abuse as a risk factor for violence in mental illness: some implications for forensic psychiatric practice and clinical ethics. Current opinion in psychiatry, 26(4), 349-354 https://doi.org/10.1097/YCO.0b013e328361e798

[2] Volkow, N. D., Fowler, J. S., Wang, G. J., Baler, R., \& Telang, F. (2009). Imaging dopamine's role in drug abuse and addiction. Neuropharmacology, 56, 3-8.

[3] Goldstein, R. Z., \& Volkow, N. D. (2011). Dysfunction of the prefrontal cortex in addiction: neuroimaging findings and clinical implications. Nature reviews neuroscience, 12(11), 652-669.

[4] Cristello, J. V., Trucco, E. M., \& Zucker, R. A. (2020). Exploring pathways to substance use: a longitudinal examination of adolescent sport involvement, aggression, and peer substance use. Addictive behaviors, 104, 106316.

[5] Wagner, E. F. (1996). Substance use and violent behavior in adolescence. Aggression and Violent Behavior, 1(4), 375-387. https://doi.org/10.1016/S1359-1789(96)00008-0.

[6] Gizewski, E. R., Müller, B. W., Scherbaum, N., Lieb, B., Forsting, M., Wiltfang, J., Leygraf, N., \& Schiffer, B. (2012). The impact of alcohol dependence on social brain function. Addiction Biology, 18, 109-120.

[7] Preller, K. H., Hulka, L. M., Vonmoos, M., Jenni, D., Baumgartner, M. R., Seifritz, E., Dziobek, I., \& Quednow, B. (2014). Impaired emotional empathy and related social network deficits in cocaine users. Addiction Biology, 19(3), 452-466.

[8] Friedman, A. S. (1998). Substance use/abuse as a predictor to illegal and violent behavior: A review of the relevant literature. Aggression and Violent Behavior, 3(4), 339-355. https://doi.org/10.1016/S1359-1789(97)00012-8.

[9] Ghossoub, E., Adib, S. M., Maalouf, F. T., Fuleihan, G. E.-H., Tamim, H., \& Nahas, Z. (2019). Association between substance use disorders and self- and other-directed aggression: 
an integrated model approach. Aggressive Behavior, 45(6), 652-661.

https://doi.org/10.1002/ab.21859

[10] Engelmann, J. M., Versace, F., Robinson, J. D., Minnix, J. A., Lam, C. Y., Cui, Y., Brown, V. L., \& Cinciripini, P. M. (2012). Neural substrates of smoking cue reactivity: A meta-analysis of fMRI studies. NeuroImage, 60(1), 252-262.

https://doi.org/https://doi.org/10.1016/j.neuroimage.2011.12.024

[11] Filbey, F., Claus, E., Audette, A. et al. Exposure to the Taste of Alcohol Elicits Activation of the Mesocorticolimbic Neurocircuitry. Neuropsychopharmacol 33, 1391-1401 (2008). https://doi.org/10.1038/sj.npp.1301513

[12] Kearney-Ramos, T. E., Dowdle, L. T., Lench, D. H., Mithoefer, O. J., Devries, W. H., George, M. S., ... Hanlon, C. A. (2018). Transdiagnostic effects of ventromedial prefrontal cortex transcranial magnetic stimulation on cue reactivity. Biological Psychiatry: Cognitive Neuroscience and Neuroimaging, 3(7), 599-609. https://doi.org/10.1016/j.bpsc.2018.03.016 [13] Kilts CD, Schweitzer JB, Quinn CK, Gross RE, Faber TL, Muhammad F, et al. (2001): Neural activity related to drug craving in cocaine addiction. Arch Gen Psychiatry 58:334-341. [14] Li Q, Li W, Wang H, Wang Y, Zhang Y, Zhu J, et al. (2015): Predicting subsequent relapse by drug-related cue-induced brain activation in heroin addiction: An event-related functional magnetic resonance imaging study. Addict Biol 20:968-978.

[15] Schacht JP, Anton RF, Myrick H (2013): Functional neuroimaging studies of alcohol cue reactivity: A quantitative meta-analysis and systematic review. Addict Biol 18:121-133 [16] Fanning, J. R., Keedy, S., Berman, M. E., Lee, R., \& Coccaro, E. F. (2017). Neural correlates of aggressive behavior in real time: A review of fMRI studies of laboratory reactive aggression. Current behavioral neuroscience reports, 4(2), 138-150. 
[17] Yang, Y., \& Raine, A. (2009). Prefrontal structural and functional brain imaging findings in antisocial, violent, and psychopathic individuals: a meta-analysis. Psychiatry Research: Neuroimaging, 174(2), 81-88.

[18] Anderson, S. W., Bechara, A., Damasio, H., Tranel, D., \& Damasio, A. R. (1999). Impairment of social and moral behavior related to early damage in human prefrontal cortex. Nature neuroscience, 2(11), 1032-1037.

[19] Blair, R. J. R. (2004). The roles of orbital frontal cortex in the modulation of antisocial behavior. Brain and cognition, 55(1), 198-208.

[20] Calzada-Reyes, A., Alvarez-Amador, A., Galán-García, L., \& Valdés-Sosa, M. (2013). EEG abnormalities in psychopath and non-psychopath violent offenders. Journal of forensic and legal medicine, 20(1), 19-26

[21] Calzada-Reyes, A., Alvarez-Amador, A., Galán-García, L., \& Valdés-Sosa, M. (2017). QEEG and LORETA in teenagers with conduct disorder and psychopathic traits. Clinical ÉEG and neuroscience, 48(3), 189-199.

[22] Krämer, U.M., Kopyciok, R.P.J., Richter, S. \& Münte, T.F. (2009). Oscillatory brain activity related to control mechanisms during laboratory-induced reactive aggression. Frontiers in behavioral neuroscience, 3, 46.

[23] Raine, A., (1993). The Psychopathology of Crime. San Diego, Academic Press.

[24] Raine, A., Lencz, T., Bihrle, S., LaCasse, L., and Colletti, P. (2000). Reduced prefrontal grey matter volume and reduced autonomic activity in antisocial personality disorder. Arch. Gen. Psychiatry 57, 119-127; discussion 128-119.

[25] Aron, A. R., Robbins, T. W., \& Poldrack, R. A. (2004). Inhibition and the right inferior frontal cortex. Trends in cognitive sciences, 8(4), 170-177.

[26] Berkman, E. T., \& Lieberman, M. D. (2009). Using neuroscience to broaden emotion regulation: theoretical and methodological considerations. Social and personality psychology compass, 3(4), 475-493.

[27] Braver, T. S., Paxton, J. L., Locke, H. S., \& Barch, D. M. (2009). Flexible neural mechanisms of cognitive control within human prefrontal cortex. Proceedings of the National Academy of Sciences, 106(18), 7351-7356.

[28] Song, M., Zhou, Y., Li, J., Liu, Y., Tian, L., Yu, C., Jiang, T. (2008). Brain spontaneous functional connectivity and intelligence. Neuroimage. 2008;41:1168-1176. 
[29] Wagner T, Fregni F, Fecteau S, Grodzinsky A, Zahn M, Pascual- Leone A (2007).

Transcranial direct current stimulation: a computer-based human model study. Neuroimage 35(3):1113-1124. doi:10.1016/j.neuroimage.2007.01.027

[30] Schneider, B., \& Koenigs, M. (2017). Human lesion studies of ventromedial prefrontal cortex. Neuropsychologia, 107, 84-93.

[31] Shamay-Tsoory, S. G., Tomer, R., Berger, B. D., \& Aharon-Peretz, J. (2003).

Characterization of empathy deficits following prefrontal brain damage: the role of the right ventromedial prefrontal cortex. Journal of cognitive neuroscience, 15(3), 324-337.

[32] Bernhardt, B.C. \& Singer, T. (2012). The neural basis of empathy. Annu Rev Neurosc. 2012; 35: 1-23.

[33] Van Dongen, J.D.M. (2020). The empathic brain of psychopaths: From social science to neuroscience in empathy. Frontiers in Psychology.

[34] Mathur, V. A., Harada, T., Lipke, T., \& Chiao, J. Y. (2010). Neural basis of extraordinary empathy and altruistic motivation. Neuroimage, 51(4), 1468-75. https://doiorg.eur.idm.oclc.org/10.1016/j.neuroimage.2010.03.025

[35] Decety, J., \& Jackson, P. L. (2004). The functional architecture of human empathy. Behavioral and cognitive neuroscience reviews, 3(2), 71-100.

[36] Decety, J., \& Lamm, C. (2009). The biological basis of empathy. Handbook of neuroscience for the behavioral sciences. New York: John Wiley and Sons, 940-957. [37] Shamay-Tsoory, S. G. (2009). Empathic processing: its cognitive and affective dimensions and neuroanatomical basis. En J., Decety \& W., Ickes,(Eds.) The Social Neuroscience of Empathy (pp. 215-232).

[38] Shamay-Tsoory, S. G. (2011). The neural bases for empathy. The Neuroscientist, 17(1), $18-24$.

[39] Blair, R. J. R. (2001). Neurocognitive models of aggression, the antisocial personality disorders, and psychopathy. Journal of Neurology, Neurosurgery \& Psychiatry, 71(6), 727731.

[40] Anderson, S. W., Barrash, J., Bechara, A., \& Tranel, D. (2006). Impairments of emotion and real-world complex behavior following childhood-or adult-onset damage to ventromedial prefrontal cortex. Journal of the International Neuropsychological Society: JINS, 12(2), 224. 
[41] Zheng, H., Huang, D., Chen, S., Wang, S., Guo, W., Luo, J., ... Chen, Y. (2016). Modulating the activity of ventromedial prefrontal cortex by anodal tDCS enhances the trustee's repayment through altruism. Frontiers in Psychology, 7 September 2016. Article 1437.

[42] Blair, K.S., Newman, C. Mitchell, D.G.V., Richell, R.A., Leonard, A. Morton, J. \& Blair, R.J.R. (2006). Differentiating among prefrontal substrates in psychopathy: neurophysiological test findings. Neuropsychology 20, 153-165.

[43] Covell, C. N., \& Scalora, M. J. (2002). Empathic deficits in sexual offenders: An integration of affective, social, and cognitive constructs. Aggression and violent behavior, 7(3), 251-270.

[44] Eisenberg, N., Eggum, N. D., \& Di Giunta, L. (2010). Empathy-related responding: Associations with prosocial behavior, aggression, and intergroup relations. Social issues and policy review, 4(1), 143-180.

[45] Giancola, P. R. (2004). Executive functioning and alcohol-related aggression. Journal of abnormal psychology, 113(4), 541.

[46] Hoaken, P. N., \& Stewart, S. H. (2003). Drugs of abuse and the elicitation of human aggressive behavior. Addictive behaviors, 28(9), 1533-1554.

[47] Marshall, W. L. (1996). Assessment, treatment, and theorizing about sex offenders: Developments during the past twenty years and future directions. Criminal Justice and Behavior, 23(1), 162-199.

[48] Miller, P. A., \& Eisenberg, N. (1988). The relation of empathy to aggressive and externalizing/antisocial behavior. Psychological bulletin, 103(3), 324.

[49] Morgan, A.B., \& Lillienfield, S.O. (2000). A meta-analytic review of the relation between antisocial behavior and neuropsychological measures of executive function. Clinical Psychology Review. 20, 113-136.

[50] Decety, J., Chen, C., Harenski, C., \& Kiehl, K. A. (2013). An fMRI study of affective perspective taking in individuals with psychopathy: imagining another in pain does not evoke empathy. Frontiers in human neuroscience, 7, 489.

[51] Koenings, M., Young, L., Adolphs, R., Tranel, D., Cushman, F., Hauser, M., \& Damasio, A. (2007). Damage to the prefrontal cortex increases utilitarian moral judgments. Nature, 446(7138), 908-11.

[52] Lockwood, P. L. (2016). The anatomy of empathy: Vicarious experience and disorders of social cognition. Behavioural brain research, 311, 255-266. 
[53] Shamay-Tsoory, S. G., Harari, H., -Peretz, J., \& Levkovitz, Y. (2010). The role of the orbitofrontal cortex in affective theory of mind deficits in criminal offenders with psychopathic tendencies. Cortex, 46(5), 668-677.

[54] Grafman, J., Schwab, K., Warden, D., Pridgen, A., Brown, H. R., \& Salazar, A. M. (1996). Frontal lobe injuries, violence, and aggression: a report of the Vietnam Head Injury Study. Neurology, 46(5), 1231-1231.

[55] Skibsted, Anine \& Cunha-Bang, Sofi \& Carré, Justin \& Hansen, Adam \& Beliveau, Vincent \& Knudsen, Gitte \& Fisher, Patrick. (2017). Aggression-related brain function assessed with the Point Subtraction Aggression Paradigm in fMRI. Aggressive Behavior. 43. 10.1002/ab.21718.

[56] Cherek, D.R. (1992). Point subtraction aggression paradigm (PSAP). Houston, University of Texas

[57] Blair, R. J. R. (2018). Traits of empathy and anger: implications for psychopathy and other disorders associated with aggression. Philos Trans R Soc Lond B Biol Sci, 373(1744). doi:10.1098/rstb.2017.0155

[58] Blair ,R.J.R. (2016). The neurobiology of impulsive aggression. J. Child Adolesc. Psychopharmacol. 26, 4-9. (doi:10.1089/cap.2015.0088)

[59] White, S. F., Brislin, S. J., Sinclair, S., \& Blair, J. R. (2014). Punishing unfairness: rewarding or the organization of a reactively aggressive response? Hum Brain Mapp, 35(5), 2137-2147. doi:10.1002/hbm.22316

[60] White, S. F., VanTieghem, M., Brislin, S. J., Sypher, I., Sinclair, S., Pine, D. S., . . Blair, R. J. (2016). Neural Correlates of the Propensity for Retaliatory Behavior in Youths With Disruptive Behavior Disorders. Am J Psychiatry, 173(3), 282-290.

doi:10.1176/appi.ajp.2015.15020250

[61] Gilam, G., Lin, T., Raz, G., Azrielant, S., Fruchter, E., Ariely, D., \& Hendler, T. (2015). Neural substrates underlying the tendency to accept anger-infused ultimatum offers during dynamic social interactions. NeuroImage, 120, 400-411. https://doi.org/10.1016/j.neuroimage.2015.07.003 [62] Gilam, G., Lin, T., Fruchter, E., \& Hendler, T. (2017). Neural indicators of interpersonal anger as cause and consequence of combat training stress symptoms. Psychological Medicine, 47(9), 1561-1572. https://doi.org/10.1017/S0033291716003354

[63] Blair, R. J. R. (2005). Applying a cognitive neuroscience perspective to the disorder of psychopathy. Development and psychopathology, 17(03), 865-891. 
[64] Blair, R. J. R. (2013). The neurobiology of psychopathic traits in youths. Nature Reviews Neuroscience, 14(11), 786-799

[65] Sergiou, C. S., Santarnecchi, E., Franken, I. H., \& van Dongen, J. D. (2020b). The effectiveness of Transcranial Direct Current Stimulation as an intervention to improve empathic abilities and reduce violent behavior: A literature review. Aggression and Violent Behavior, 101463.

[66] Chen, C. Y. (2018). Right ventrolateral prefrontal cortex involvement in proactive and reactive aggression: A transcranial direct current stimulation study. NeuroReport, 29(17), $1509-1515$.

[67] Yu, J., Tseng, P., Hung, D. L., Wu, S. W., \& Juan, C. H. (2015). Brain stimulation improves cognitive control by modulating medial-frontal activity and preSMA-vmPFC functional connectivity. Human Brain Mapping, 36(10), 4004-4015. https://doi.org/10. 1002/hbm.22893.

[68] Gilam, G., Abend, R., Gurevitch, G., Erdman, A., Baker, H., Ben-Zion, Z., \& Hendler, T. (2018). Attenuating anger and aggression with neuromodulation of the vmPFC: A simultaneous tDCS-fMRI study. Cortex, 109, 156-170.

https://doi.org/10.1016/j.cortex.2018.09.010

[69] Abend, R., Sar-el, R., Gonen, T., Jalon, I., Vaisvaser, S., Bar-Haim, Y., \& Hendler, T. (2018). Modulating Emotional Experience Using Electrical Stimulation of the MedialPrefrontal Cortex: A Preliminary tDCS-fMRI Study. Neuromodulation, 22(8), 884-893. https://doi.org/10.1111/ner.127878.

[70] Fumagalli, M., Vergari, M., Pasqualetti, P., Marceglia, S., Mameli, F., Ferrucci, R., Mrakic-Sposta, S., Zago, S., Sartori, G., Pravettoni, G., Barbieri, S., Cappa, S., \& Priori, A. (2010). Brain switches utilitarian behavior: Does gender make the difference? PLoS ONE, 5(1), https://doi.org/10.1371/journal.pone.0008865.

[71] Riva, P., Lauro, L. J. R., DeWall, C. N., Chester, D. S., \& Bushman, B. J. (2015). Reducing aggressive responses to social exclusion using transcranial direct current stimulation.

[72] Barr, M. S., Fitzgerald, P. B., Farzan, F., George, T. P., \& Daskalakis, Z. J. (2008). Transcranial magnetic stimulation to understand the pathophysiology and treatment of substance use disorders. Current Drug Abuse Reviews, 1, 328-339.

[73] George, M. S., \& Aston-Jones, G. (2010). Noninvasive techniques for probing neurocircuitry and treating illness: Vagus nerve stimulation (VNS), transcranial magnetic stimulation (TMS) and transcranial direct current stimulation (tDCS). 
Neuropsychopharmacology: Official Publication of the American College of Neuropsychopharmacology, 35, 301-316.

[74] Jansen, J. M., Daams, J. G., Koeter, M. W. J., Veltman, D. J., van den Brink, W., \& Goudriaan, A. E. (2013). Effects of non-invasive neurostimulation on craving: A metaanalysis. Neuroscience and Biobehavioral Reviews, 37, 2472-2480.

[75] Nitsche, M. A., \& Paulus, W. (2000). Excitability changes induced in the human motor cortex by weak transcranial direct current stimulation. Journal of Physiology, 527, 633-639. [76] Nitsche, M. A., Schauenberg, A., Lang, N., Liebetanz, D., Exner, C., Paulus, W., et al. (2003). Facilitation of implicit motor learning by weak transcranial direct current stimulation of the primary motor cortex in the human. J Cogn Neuroscience, 15(4), 619-626 2003. May 15.

[77] Brunoni, A.R., Ferrucci, R., Bortolomasi, M., et al. (2013). Interactions between transcranial direct current stimulation (tDCS) and pharmacological interventions in the major depressive episode: findings from a naturalistic study. European Psychiatry, 28(6), 356-61. [78] Rohan, J. G., Carhuatanta, K. A., McInturf, S. M., Miklasevich, M. K., \& Jankord, R. (2015). Modulating hippocampal plasticity with in vivo brain stimulation. Journal of Neuroscience, 35(37), 12824-12832.

[79] Woods, A. J., Antal, A., Bikson, M., Boggio, P. S., Brunoni, A. R., Celnik, P., ... \& Knotkova, H. (2016). A technical guide to tDCS, and related non-invasive brain stimulation tools. Clinical neurophysiology, 127(2), 1031-1048.

[80] Ling, S., Raine, A., Choy, O., \& Hamilton, R. (2020). Effects of prefrontal cortical stimulation on aggressive and antisocial behavior: A double-blind, stratified, randomized, sham-controlled, parallel-group trial. JOURNAL OF EXPERIMENTAL CRIMINOLOGY. [81] Batsikadze, G., Moliadze, V., Paulus, W., Kuo, M. F., \& Nitsche, M. A. (2013). Partially non-linear stimulation intensity-dependent effects of direct current stimulation on motor cortex excitability in humans. The Journal of Physiology, 591(7), 1987-2000. https://doi.org/10.1113/jphysiol.2012.249730.

[82] Nissim, N.R., O’Shea, A., Indahlastari, A., Telles, R., Richards, L., Porges, E., Cohen, R., \& Woods, A.J., (2019). Effects of in-Scanner Bilateral Frontal tDCS on Functional Connectivity of the Working Memory Network in Older Adults. Front. Aging Neurosci., 15 March 2019.

[83] Samani, M. M., Agboada, D., Jamil, A., Kuo, M. F., \& Nitsche, M. A. (2013). Titrating the neuroplastic effects of cathodal transcranial direct current stimulation (tDCS) over the primary motor cortex. Cortex, 119(October 2019), 350-361. 
[84] Bienenstock, E. L., Cooper, L. N, and Munro, P. W. (1982). Theory for the development of neuron selectivity: orientation specificity and binocular interaction in visual cortex. Journal of Neuroscience, 2:32-48.

[85] Abraham WC, Tate WP. Metaplasticity: a new vista across the field of synaptic plasticity. Prog Neurobiol 1997;52(4):303e23.

[86] Hassanzahraee M, Zoghi M, Jaberzadeh S. How different priming stimulations affect the corticospinal excitability induced by noninvasive brain stimulation techniques: a systematic review and meta-analysis. Rev Neurosci 2018;29(8):883e99.

[87] Karabanov A, Ziemann U, Hamada M, George M, Quartarone A, et al. Consensus paper: probing homeostatic plasticity of human cortex with noninvasive transcranial brain stimulation. Brain Stimul 2015;8:442e54.

[88] Müller-Dahlhaus F, Ziemann U. Metaplasticity in human cortex. Neuroscientist 2015;21(2):185e202.

[89] Krönberg, G., Bridi, M., Abel, T., Bikson, M., Parra., L.C. (2018). Direct current stimulation modulates LTP and LTD: activity dependence and dendritic effects. Brain Stimul. 2017; 10(1): 51-58. doi:10.1016/j.brs.2016.10.001

[90] Bikson, M., Esmaeilpour, Z., Adair, D., Kronberg, G., Tyler, W. J., Antal, A., ... \& Edwards, D.(2019). Transcranial electrical stimulation nomenclature. Brain stimulation, 12(6), 1349-1366. https://doi.org/10.1016/j.brs.2019.07.010.

[91] DaSilva, A. F., Truong, D. Q., DosSantos, M. F., Toback, R. L., Datta, A., \& Bikson, M.(2015). State-of-art neuroanatomical target analysis of high-definition and conventional tDCS montages used for migraine and pain control. Frontiers in neuroanatomy, 9, 89. https://doi.org/10.3389/fnana.2015.00089.

[92] Edwards, D., Cortes, M., Datta, A., Minhas, P., Wassermann, E.M., Bikson, M. (2013). Physiological and modeling evidence for focal transcranial electrical brain stimulation in humans: a basis for high-definition tDCS. Neuroimage, 74, 266-75.

[93] Hess, C.W. (2013). Modulation of cortical-subcortical networks in Parkinson's disease by applied field effects. Front Hum Neurosci 7:565. doi:10.3389/fnhum.2013.00565.

[94] Nakamura-Palacios, E. M., Lopes, I. B. C., Souza, R. A., Klauss, J., Batista, E. K., Conti, C. L., ... \& de Souza, R. S. M. (2016). Ventral medial prefrontal cortex (vmPFC) as a target of the dorsolateral prefrontal modulation by transcranial direct current stimulation (tDCS) in drug addiction. Journal of Neural Transmission, 123(10), 1179-1194. 
[95] Manuel, A. L., David, A. W., Bikson, M., \& Schnider, A. (2014). Frontal tDCS modulates orbitofrontal reality filtering. Neuroscience, 265, 21-27.

[96] Tanaka, T., Takano, Y., Tanaka, S., Hironaka, N., Kobayashi, K., Hanakawa, T., ... \& Honda, M. (2013). Transcranial direct-current stimulation increases extracellular dopamine levels in the rat striatum. Frontiers in systems neuroscience, 7, 6.

[97] Faria, P., Hallett, M., \& Miranda, P. C. (2011). A finite element analysis of the effect of electrode area and inter-electrode distance on the spatial distribution of the current density in tDCS. Journal of neural engineering, 8(6), 066017. http://dx.doi.org/10.1088/1741-2560/8/6/066017

[98] To, W. T., Eroh, J., Hart, J., \& Vanneste, S. (2018). Exploring the effects of anodal and cathodal high definition transcranial direct current stimulation targeting the dorsal anterior cingulate cortex. Scientific reports, 8(1), 4454. doi:10.1038/s41598-01822730-x.

[99] Baxter, B.S., Edelman, B.J., Sohrabpour, A., \& He, B. (2017). Anodal Transcranial Direct Current Stimulation Increases Bilateral Direct Brain Connectivity during MotorImagery Based Brain-Computer Interface Control. Front. Neurosci, 07 December 2017. [100] Buch, E. R., Santarnecchi, E., Antal, A., Born, J., Celnik, P. A., Classen, J., et al. (2017). Effects of tDCS on motor learning and memory formation: a consensus and critical position paper. Clin. Neurophysiol. 128, 589-603. doi: 10.1016/j.clinph.2017.01.004 [101] Fisher, D. B., Fried, P., Ruffini, G., Ripolles, O., Ketchabaw, T., Santarnecchi, E., et al. (2017). Network-targeted non-invasive brain stimulation with multifocal tdcs. Brain Stimul. 10, 411-412. doi: 10.1016/j.brs.2017.01.219 [102] Fox, M. D., Buckner, R. L., Liu, H., Chakravarty, M. M., Lozano, A. M., and PascualLeone, A. (2014). Resting-state networks link invasive and noninvasive brain stimulation across diverse psychiatric and neurological diseases. Proc. Natl. Acad. Sci. U.S.A. 111, E4367-E4375. doi: 10.1073/pnas.1405003111.

[103] Cheng, Y., Hung, A., \& Decety, J. (2012). Dissociation between affective sharing and emotion understanding in juvenile psychopaths. 24, 623-636.

https://doi.org/10.1017/S095457941200020X

[104] Decety, J., Chen, C., Harenski, C. L., \& Kiehl, K. A. (2015). Socioemotional Processing of Morally- Laden Behavior and Their Consequences on Others in Forensic Psychopaths. 2026(January), 2015-2026. https://doi.org/10.1002/hbm.22752 [105] Van Dongen, J. D. M., Brazil, I. A., Van Der Veen, F. M., \& Franken, I. H. A. (2018). 
Electrophysiological correlates of empathic processing and its relation to psychopathic meanness. Neuropsychology, 32(8), 996-1006. https://doi.org/10.1037/neu0000477. [106] Decety, J., Yang, C. Y., \& Cheng, Y. (2010). Physicians down-regulate their pain empathy response: an event-related brain potential study. Neuroimage, 50(4), 1676-1682. [107] Meng, J., Meriño, L. M., Shamlo, N. B., Makeig, S., Robbins, K., \& Huang, Y. (2012). Characterization and robust classification of EEG signal from image RSVP events with independent time-frequency features. PloS one, 7(9), e44464.

[108] Corbera, S., Cook, K., Brocke, S., Dunn, S., Wexler, B. E., \& Assaf, M. (2014, May). The Relationship Between Social Competence Deficits and Empathy for Emotional Pain in Schizophrenia. In BIOLOGICAL PSYCHIATRY (Vol. 75, No. 9, pp. 200S-200S). 360 PARK AVE SOUTH, NEW YORK, NY 10010-1710 USA: ELSEVIER SCIENCE INC. [109] Fabi, S., \& Leuthold, H. (2017). Empathy for pain influences perceptual and motor processing: Evidence from response force, ERPs, and EEG oscillations. Social Neuroscience, 12(6), 701-716.

[110] Vaes, J., Meconi, F., Sessa, P., \& Olechowski, M. (2016). Minimal humanity cues induce neural empathic reactions towards non-human entities. Neuropsychologia, 89, 132 140.

[111] Hajcak, G., MacNamara, A., \& Olvet, D. M. (2010). Event-related potentials, emotion, and emotion regulation: an integrative review. Developmental neuropsychology, 35(2), 129155.

[112] Cuthbert, B. N., Schupp, H. T., Bradley, M. M., Birbaumer, N., \& Lang, P. J. (2000). Brain potentials in affective picture processing: covariation with autonomic arousal and affective report. Biological psychology, 52(2), 95-111.

[113] Fan, Y., \& Han, S. (2008). Temporal dynamic of neural mechanisms involved in empathy for pain: An event-related brain potential study. Neuropsychologia, 46(1), 160173.https://doi.org/10.1016/j.neuropsychologia.2007.07.023.

[114] Ibáñez, A., Hurtado, E., Lobos, A., Escobar, J., Trujillo, N., Baez, S., ... \& Decety, J. (2011). Subliminal presentation of other faces (but not own face) primes behavioral and evoked cortical processing of empathy for pain. Brain research, 1398, 72-85.

[115] Li, W., \& Han, S. (2010). Perspective taking modulates event-related potentials to perceived pain. Neuroscience letters, 469(3), 328-332.

[116] Coll, M. P. (2018). Meta-analysis of ERP investigations of pain empathy underlines methodological issues in ERP research. Social Cognitive and Affective Neuroscience, 13(10), 1003-1017. 
[117] Hajcak, G., Weinberg, A., MacNamara, A., \& Foti, D. (2012). ERPs and the study of emotion.

[118] Lang, P. J., \& Bradley, M. M. (2010). Emotion and the motivational brain. Biological psychology, 84(3), 437-450.

[119] Fan, Y., Duncan, N. W., de Greck, M., \& Northoff, G. (2011). Is there a core neural network in empathy? An fMRI based quantitative meta-analysis. Neuroscience and Biobehavioral Reviews, 35(3), 903-911. https://doi.org/10.1016/j.neubiorev.2010.10.009 [120] Nissim, N.R., O’Shea, A., Indahlastari, A., Telles, R., Richards, L., Porges, E., Cohen, R., \& Woods, A.J., (2019). Effects of in-Scanner Bilateral Frontal tDCS on Functional Connectivity of the Working Memory Network in Older Adults. Front. Aging Neurosci., 15 March 2019

[121] Chbosky, S. (Director). (2017). Wonder [Film]. Lionsgate

[122] Nelson, J. (Director). (2001). I am Sam [Film]. Bedford Falls Production.

[123] Baron-Cohen, S., Wheelwright, S., Hill, J., Raste, Y., \& Plumb, I. (2001). The "Reading the Mind in the Eyes" Test revised version: a study with normal adults, and adults with Asperger syndrome or high-functioning autism. The Journal of Child Psychology and Psychiatry and Allied Disciplines, 42(2), 241-251.

[124] General Assembly of the World Medical Association. (2014). World Medical Association Declaration of Helsinki: ethical principles for medical research involving human subjects. The Journal of the American College of Dentists, 81(3), 14.

[125] Sergiou, C. S., Woods, A. J., Franken, I. H., \& van Dongen, J. D. (2020a). Transcranial direct current stimulation (tDCS) as an intervention to improve empathic abilities and reduce violent behavior in forensic offenders: study protocol for a randomized controlled trial. Trials, 21(1), 1-14.

[126] Neuroelectrics Barcelona, SLU, (2011).

[127] Lefaucheur, J. P., Antal, A., Ayache, S. S., Benninger, D. H., Brunelin, J., Cogiamanian, F., ... \& Marangolo, P. (2017). Evidence-based guidelines on the therapeutic use of transcranial direct current stimulation (tDCS). Clinical Neurophysiology, 128(1), 5692.

[128] Thielscher, A., Antunes, A., Saturnino, G.B., 2015. Field modeling for transcranial magnetic stimulation: A useful tool to understand the physiological effects of TMS? Annu Int Conf IEEE Eng Med Biol Soc 2015, 222-225. https://doi.org/10.1109/EMBC.2015.7318340. 
[129] Geuzaine, C., \& Remacle, J.-F., 2008. Gmsh reference manual: the documentation for Gmsh, a finite element mesh generator with built-in pre-and post-processing facilities. URL http://www. geuz. org/gmsh.

[130] Gandiga, P.C., Hummel, F.C., \& Cohen, L.G. (2006). Transcranial DC Stimulation (tDCS): a tool for double-blind sham-controlled clinical studies in brain stimulation. Clin Neurophysiol. 2006 Apr;117(4):845-50.

[131] Geniole, S.N., MacDonell, E.T., \& McCormick, C.M. (2016). The Point Subtraction Paradigm as a laboratory tool for investigating the neuroendocrinology of competition. Hormones and Behavior, Online First.

[132] Raine, A., Dodge, K., Loeber, R., Gatzke-Kopp, L., Lynam, D., Reynolds, C., ... \& Liu, J. (2006). The reactive-proactive aggression questionnaire: Differential correlates of reactive and proactive aggression in adolescent boys. Aggressive Behavior: Official Journal of the International Society for Research on Aggression, 32(2), 159-171.

[133] Cima, M., Raine, A., Meesters, C., \& Popma, A. (2013). Validation of the Dutch Reactive Proactive Questionnaire (RPQ): Differential Correlates of Reactive and Proactive Aggression From Childhood to Adulthood. Aggressive Behavior, 39(2), 99-113.

[134] Davis, M. H. (1980). A multidimensional approach to individual differences in empathy. JSAS Catalog of Selected Documents in Psychology, 10, 85.

[135] de Corte, K., Buysse, A., Verhofstadt, L., Roeyers, H., Ponnet, K., \& Davis, M. (2007). Measuring empathic tendencies: Reliability and validity of the Dutch version of the Interpersonal Reactivity Index. Psychologica Belgica, 47(4).

[136] Babor, T.F., Higgins-Biddle, J.C., Saunders, J.B. \& Monteiro, M.G. (2001). The Alcohol Use Disorders Identification Test: Guidelines for Use in Primary Care World Health Organization (WHO Publication Februari 2014. Diagnostische instrumenten. Kenniscentrum Kinder- en Jeugdpsychiatrie No. 01.6a), World Health Organization, Geneva, Switzerland. [137] Allen, J. P., Litten, R. Z., Fertig, J. B., \& Babor, T. (1997). A review of research on the Alcohol Use Disorders Identification Test (AUDIT). Alcoholism: clinical and experimental research, 21(4), 613-619.

[138] Berman, A. H., Bergman, H., Palmstierna, T., \& Schlyter, F. (2005). Evaluation of the Drug Use Disorders Identification Test (DUDIT) in Criminal Justice and Detoxification Settings and in a Swedish Population Sample. European Addiction Research, 11(1), 22-31. [139] Berman, A. H., Palmstierna, T., Källmén, H., \& Bergman, H. (2007). The self-report drug use disorders identification test - extended (DUDIT-E): reliability, validity, and motivational index. Journal of Substance Abuse Treatment, 32(4), 357-369. 
[140] LiveAmp (32 channels) [Apparatus]. (2018). Gilching, Germany: Brain Products $\mathrm{GmbH}$.

[141] BrainVision Analyzer (Version 2.2.0) [Computer software]. (2019). Gilching, Germany: Brain Products GmbH.

[142] Gratton, G., Coles, M. G., \& Donchin, E. (1983). A new method for off-line removal of ocular artifact. Electroencephalography and clinical neurophysiology, 55(4), 468-484.

[143] Ikezawa, S., Corbera, S., \& Wexler, B. E. (2014). Emotion self-regulation and empathy depend upon longer stimulus exposure. Social cognitive and affective neuroscience, 9(10), 1561-1568.

[144] Polich, J. (2007). Updating P300: an integrative theory of P3a and P3b. Clinical neurophysiology, 118(10), 2128-2148.

[145] Hajcak, G., Dunning, J. P., \& Foti, D. (2009). Motivated and controlled attention to emotion: time-course of the late positive potential. Clinical neurophysiology, 120(3), 505510.

[146] IBM Corp. Released 2017. IBM SPSS Statistics for Mac, Version 25.0. Armonk, NY: IBM Corp.

[147] Cohen, J. (1988). Statistical Power Analysis for the Behavioral Sciences. New York: Routledge, https://doi.org/10.4324/9780203771587

[148] Hajcak, G., Holroyd, C. B., Moser, J. S., \& Simons, R. F. (2005). Brain potentials associated with expected and unexpected good and bad outcomes. Psychophysiology, 42(2), 161-170.

[149] Sailer, U., Fischmeister, F. P. S., \& Bauer, H. (2010). Effects of learning on feedbackrelated brain potentials in a decision-making task. Brain research, 1342, 85-93. [150] Yeung, N., Botvinick, M. M., \& Cohen, J. D. (2004). The neural basis of error detection: conflict monitoring and the error-related negativity. Psychological review, 111(4), 931.

[151] Duncan-Johnson, C. C., \& Donchin, E. (1977). On quantifying surprise: The variation of event-related potentials with subjective probability. Psychophysiology, 14(5), 456-467. [152] Donchin, E., \& Coles, M. G. (1988). Is the P300 component a manifestation of context updating?. Behavioral and brain sciences, 11(3), 357-374.

[153] Kompatsiari, K., Candrian, G., \& Mueller, A. (2016). Neuroscience Letters, 617 (2016), pp. 166-172, 10.1016/j.neulet.2016.02.012 
[154] Groen, Y., Wijers, A. A., Mulder, L. J., Minderaa, R. B., \& Althaus, M. (2007).

Physiological correlates of learning by performance feedback in children: a study of EEG event-related potentials and evoked heart rate. Biological Psychology, 76(3), 174-187.

[155] Jongsma, M. L., Eichele, T., Van Rijn, C. M., Coenen, A. M., Hugdahl, K., Nordby, H., \& Quiroga, R. Q. (2006). Tracking pattern learning with single-trial event-related potentials. Clinical Neurophysiology, 117(9), 1957-1973.

[156] Lindín, M., Zurrón, M., \& Díaz, F. (2004). Changes in P300 amplitude during an active standard auditory oddball task. Biological psychology, 66(2), 153-167.

[157] Radlo, S. J., Janelle, C. M., Barba, D. A., \& Frehlich, S. G. (2001). Perceptual decision making for baseball pitch recognition: using P300 latency and amplitude to index attentional processing. Research quarterly for exercise and sport, 72(1), 22-31.

[158] Francis, J.T., Gluckman, B.J., Schiff, S.J., 2003. Sensitivity of Neurons to Weak Electric Fields. J. Neurosci. 23, 7255-7261. https://doi.org/10.1523/JNEUROSCI.23-1907255.2003

[159] Geuzaine, C., Remacle, J.-F., 2008. Gmsh reference manual: the documentation for Gmsh, a finite element mesh generator with built-in pre-and post-processing facilities. URL http://www. geuz. org/gmsh.

[160] Liu, A., Vöröslakos, M., Kronberg, G., Henin, S., Krause, M.R., Huang, Y., Opitz, A., Mehta, A., Pack, C.C., Krekelberg, B., Berényi, A., Parra, L.C., Melloni, L., Devinsky, O., Buzsáki, G., 2018. Immediate neurophysiological effects of transcranial electrical stimulation. Nature Communications 9. https://doi.org/10.1038/s41467-018-07233-7

[161] Rahman, A. et al. Cellular effects of acute direct current stimulation: somatic and synaptic terminal effects. J Physiol 591, 2563-2578 (2013).

[162] Metwally, M. K., Han, S. M. \& Kim, T. S. The effect of tissue anisotropy on the radial and tangential components of the electric field in transcranial direct current stimulation. Med Biol Eng Comput 53, 1085-1101 (2015).

[163] Huang, Y. et al. Measurements and models of electric fields in the in vivo human brain during transcranial electric stimulation. Elife, 6 (2017).

[164] Bikson, M. et al. Effects of uniform extracellular DC electric fields on excitability in rat hippocampal slices in vitro. J Physiol 557,

175-190 (2004).

[165] Dmochowski, J. P., Koessler, L., Norcia, A. M., Bikson, M. \& Parra, L. C. Optimal use of EEG recordings to target active brain areas with transcranial electrical stimulation.

NeuroImage 157, 69-80 (2017). 
[166] Choy, O., Raine, A., \& Hamilton, R. H. (2018). Stimulation of the prefrontal cortex reduces intentions to commit aggression: A randomized, double-blind, placebo-controlled, stratified, parallel-group trial. Journal of Neuroscience, 38(29), 6505-6512. https://doi.org/10.1523/JNEUROSCI.3317-17.2018 [167] Molero-Chamizo, A., Martín Riquel, R., Moriana, J. A., Nitsche, M. A., \& RiveraUrbina, G. N. (2019). Bilateral Prefrontal Cortex Anodal tDCS Effects on Self-reported Aggressiveness in Imprisoned Violent Offenders. Neuroscience, 397, 31-40. https://doi.org/10.1016/j.neuroscience.2018.11.018 [168] Afifi, L., Jarrett Rushmore, R., \& Valero-Cabré, A. (2013). Benefit of multiple sessions of perilesional repetitive transcranial magnetic stimulation for an effective rehabilitation of visuospatial function. European Journal of Neuroscience, 37(3), 441-454.

[169] Mancuso, L.E., Ilieva, I.P., Hamilton, R.H., Farah, M.J. (2016). Does transcranial direct current stimulation improve healthy work- ing memory?: a meta-analytic review. Journal of Cognitive Neu- roscience, 28(8), 1063-89.

[170] Monte-Silva, K., Kuo, M. F., Hessenthaler, S., Fresnoza, S., Liebetanz, D., Paulus, W., \& Nitsche, M. A. (2013). Induction of late LTP-like plasticity in the human motor cortex by repeated non-invasive brain stimulation. Brain stimulation, 6(3), 424-432.

[171] Reis, J., Schambra, H. M., Cohen, L. G., Buch, E. R., Fritsch, B., Zarahn, E., ... \& Krakauer, J. W. (2009). Noninvasive cortical stimulation enhances motor skill acquisition over multiple days through an effect on consolidation. Proceedings of the National Academy of Sciences, 106(5), 1590-1595.

[172] Valero-Cabré, A., Pascual-Leone, A., \& Rushmore, R. J. (2008). Cumulative sessions of repetitive transcranial magnetic stimulation (rTMS) build up facilitation to subsequent TMS-mediated behavioural disruptions. European Journal of Neuroscience, 27(3), 765-774. [173] Song, S., Zilverstand, A., Gui, W., Li, H.J., Zhou, X. (2019). Effects of single-session versus multi-session non-invasive brain stimulation on craving and consumption in individuals with drug addiction, eating disorders or obesity: A meta-analysis. Brain Stimul. 2019 May-Jun;12(3):606-618. doi: 10.1016/j.brs.2018.12.975. Epub 2018 Dec 27. PMID: 30612944.

[174] Zanardi, R., Poletti, S., Prestifilippo, D., Attanasio, F., Barbini, B., \& Colombo, C. (2020). Transcranial direct current stimulation: A novel approach in the treatment of vascular depression. Brain Stimulation, 13(6), 1559-1565. https://doi.org/https://doi.org/10.1016/j.brs.2020.08.013 
[175] Dell’Osso, B., Zanoni, S., Ferrucci, R., Vergari, M., Castellano, F., D’Urso, N., Dobrea, C., Benatti, B., Arici, C., Priori, A., \& Altamura, A. C. (2012). Transcranial direct current stimulation for the outpatient treatment of poor-responder depressed patients. European Psychiatry, 27(7), 513-517. https://doi.org/https://doi.org/10.1016/j.eurpsy.2011.02.008 [176] Rushmore, R. J., DeSimone, C., \& Valero-Cabré, A. (2013). Multiple sessions of transcranial direct current stimulation to the intact hemisphere improves visual function after unilateral ablation of visual cortex. European Journal of Neuroscience, 38(12), 3799-3807. [177] Bikson, M., Rahman, A., Datta, A. (2012). Computational models of transcranial direct current stimulation. Clinical EEG and Neuroscience, 43(3), 176-83.

[178] Raine, A. (2019). The neuromoral theory of antisocial, violent, and psychopathic behavior. Psychiatry Research. https://doi.org/10.1016/j.psychres.2018.11.025. 


\section{Tables}

\section{Table 1}

Demographic characteristics

tDCS group Sham group

\begin{tabular}{lccll} 
& $n$ & $\%$ & $n$ & $\%$ \\
\hline Caucasian & 25 & 100 & 23 & 92 \\
Non- Caucasian & 0 & - & 2 & 8 \\
Primary education & 9 & 36 & 8 & 32 \\
High School & 7 & 28 & 6 & 24 \\
Secondary education (VET) & 9 & 36 & 11 & 44 \\
DSM-5 Axis I & 7 & 28 & 10 & 40 \\
DSM-5 Axis II & 8 & 32 & 10 & 40 \\
Mono substance use & 8 & 32 & 9 & 36 \\
Poly substance use & 17 & 68 & 16 & 64
\end{tabular}

*Note. Characteristics are displayed in percentage of participants per group, $\mathrm{N}=50$ ( $n=25$ for each condition). Participants were on average 36.4 years old $(\mathrm{SD}=8.88)$ in the tDCS group and on average 38.4 years in the sham group $(\mathrm{SD}=9.56)$, and participant age did not differ by condition. VET= Vocational Education and Training, DSM-5= Diagnostic Symptom Manual fifth edition. 


\section{Table 2}

Descriptive statistics for self-report questionnaires, rating task, PSAP, P3 and LPP amplitudes

$$
\text { tDCS group Sham group }
$$

Time I (pretest)

\begin{tabular}{|c|c|c|c|c|c|c|}
\hline Variable & $M$ & $S D$ & Range & $M$ & $S D$ & Range \\
\hline DIFF_AROUSAL & 2.52 & 2.14 & (-) $.40-7.28$ & 3.99 & 2.49 & $.08-7.47$ \\
\hline DIFF_EMOTION & (-) 1.15 & 2.34 & (-) $4.15-4.63$ & (-) 2.18 & 2.35 & (-) $6.95-3.3$ \\
\hline DIFF_VICTIM & 1.76 & 1.89 & (-) $3.07-5.05$ & 2.11 & 2.60 & (-) $3.42-6.65$ \\
\hline DIFF_PERPETRATOR & (-) 1.22 & 1.99 & (-) $3.75-4.00$ & (-) 2.33 & 2.05 & (-) 6.80-1.60 \\
\hline PSAP & .12 & .09 & $.0-.47$ & .09 & .10 & $.00-.37$ \\
\hline RPQ Total & 21.08 & 8.14 & $6-43$ & 17.68 & 8.61 & $6-39$ \\
\hline RPQ Reactive & 12.48 & 4.01 & $3-22$ & 11.40 & 4.37 & $4-22$ \\
\hline RPQ Proactive & 8.60 & 4.69 & $2-21$ & 6.28 & 4.82 & $0-17$ \\
\hline IRI Total & 55.00 & 14.73 & $26-84$ & 56.60 & 14.60 & $33-88$ \\
\hline SRP-SF Total & 78.56 & 14.28 & $54-98$ & 72.88 & 20.54 & $43-133$ \\
\hline AUDIT & 12.35 & 12.61 & $0-37$ & 11.41 & 12.76 & $0-40$ \\
\hline DUDIT & 22.44 & 12.51 & $0-40$ & 18.74 & 13.63 & $0-40$ \\
\hline P3 AMPLITUDE NEU & 2.41 & 5.23 & (-) 7.91-11.59 & 2.93 & 4.25 & (-) 4.87-11.89 \\
\hline P3 AMPLITUDE AGG & 3.34 & 4.38 & (-) 5.56-14.14 & 3.21 & 4.97 & $(-) 8.74-12.82$ \\
\hline LPP AMPLITUDE NEU & 1.29 & 6.86 & $(-) 18.21-15.19$ & 1.76 & 4.85 & $(-) 9.92-11.52$ \\
\hline LPP AMPLITUDE AGG & 2.42 & 5.48 & $(-) 13.43-10.23$ & 3.27 & 5.85 & $(-) 10.13-13.13$ \\
\hline
\end{tabular}

*Note. PSAP= Point Subtraction Aggression Paradigm, RPQ = Reactive Proactive Aggression Questionnaire, IRI = Interpersonal Reactivity Index, SRP-SF= Self-Report Psychopathy Short Form, AUDIT= Alcohol Use Disorder Identification Test, DUDIT $=$ Drug Use Disorder Identification Test, P3= P300, LPP $=$ Late Positive Potential, NEU = Neutral condition, $\mathrm{AGG}=$ aggression condition . 
Table 2 Continued.

tDCS group

Sham group

Time II (posttest)

\begin{tabular}{lcclcccc}
\multicolumn{1}{c}{ Variable } & $M$ & $S D$ & Range & $M$ & $S D$ & \multicolumn{1}{l}{ Range } \\
\hline DIFF_AROUSAL & 2.78 & 2.44 & $(-) 1.05-7.55$ & 3.29 & 2.61 & $(-) .23-7.60$ \\
DIFF_EMOTION & $(-)$ & 1.38 & 2.33 & $(-) 5.72-3.45$ & $(-) 1.73$ & 2.17 & $(-) 7.25-1.90$ \\
DIFF_VICTIM & 1.45 & 2.24 & $(-) 4.00-3.78$ & 1.27 & 2.86 & $(-) 3.75-7.60$ \\
DIFF_PERPETRATOR & $(-)$ & 1.74 & 3.77 & $(-)) 3.95-3.77$ & $(-) 1.67$ & 2.34 & $(-) 7.60-2.60$ \\
PSAP & .07 & .07 & $.0-.33$ & .15 & .19 & $0-66$ \\
RPQ Total & 18.58 & 9.66 & $8-45$ & 16.36 & 8.53 & $2-36$ \\
RPQ Reactive & 11.20 & 4.71 & $3-22$ & 10.32 & 4.25 & $2-20$ \\
RPQ Proactive & 7.37 & 5.54 & $0-23$ & 6.04 & 4.75 & $0-16$ \\
IRI Total & 56.30 & 10.45 & $39-75$ & 56.45 & 12.66 & $37-80$ \\
SRP-SF Total & 74.96 & 18.09 & $37-113$ & 65.32 & 15.85 & $28-99$ \\
AUDIT & 13.76 & 13.03 & $0-37$ & 8.36 & 9.18 & $0-33$ \\
DUDIT & 19.95 & 11.59 & $0-38$ & 14.47 & 12.20 & $0-38$ \\
P3 AMPLITUDE NEU & 3.13 & 2.99 & $(-) 1.87-8.65$ & 0.51 & 3.96 & $(-) 8.14-8.89$ \\
P3 AMPLITUDE AGG & 4.18 & 3.85 & $(-) 1.87-13.59$ & 1.79 & 6.12 & $(-) 12.57-14.73$ \\
LPP AMPLITUDE NEU & 2.15 & 5.87 & $(-) 19.45-10.44$ & $(-) .11$ & 3.79 & $(-) 12.88-5.68$ \\
LPP AMPLITUDE AGG & 5.20 & 3.65 & $(-) .89-13.09$ & 2.82 & 6.04 & $(-) 17.48-12.18$
\end{tabular}

*Note. PSAP= Point Subtraction Aggression Paradigm, RPQ = Reactive Proactive Aggression Questionnaire, IRI = Interpersonal Reactivity Index, SRP-SF= Self-Report Psychopathy Short Form, AUDIT= Alcohol Use Disorder Identification Test, DUDIT $=$ Drug Use Disorder Identification Test, P3= P300, LPP = Late Positive Potential, NEU = Neutral condition, AGG = aggression condition. 
A

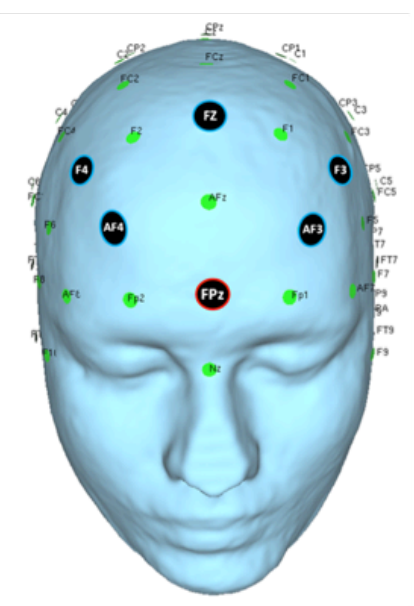

C

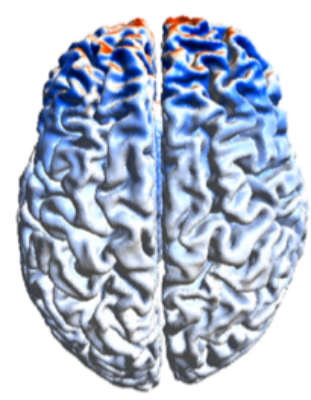

B
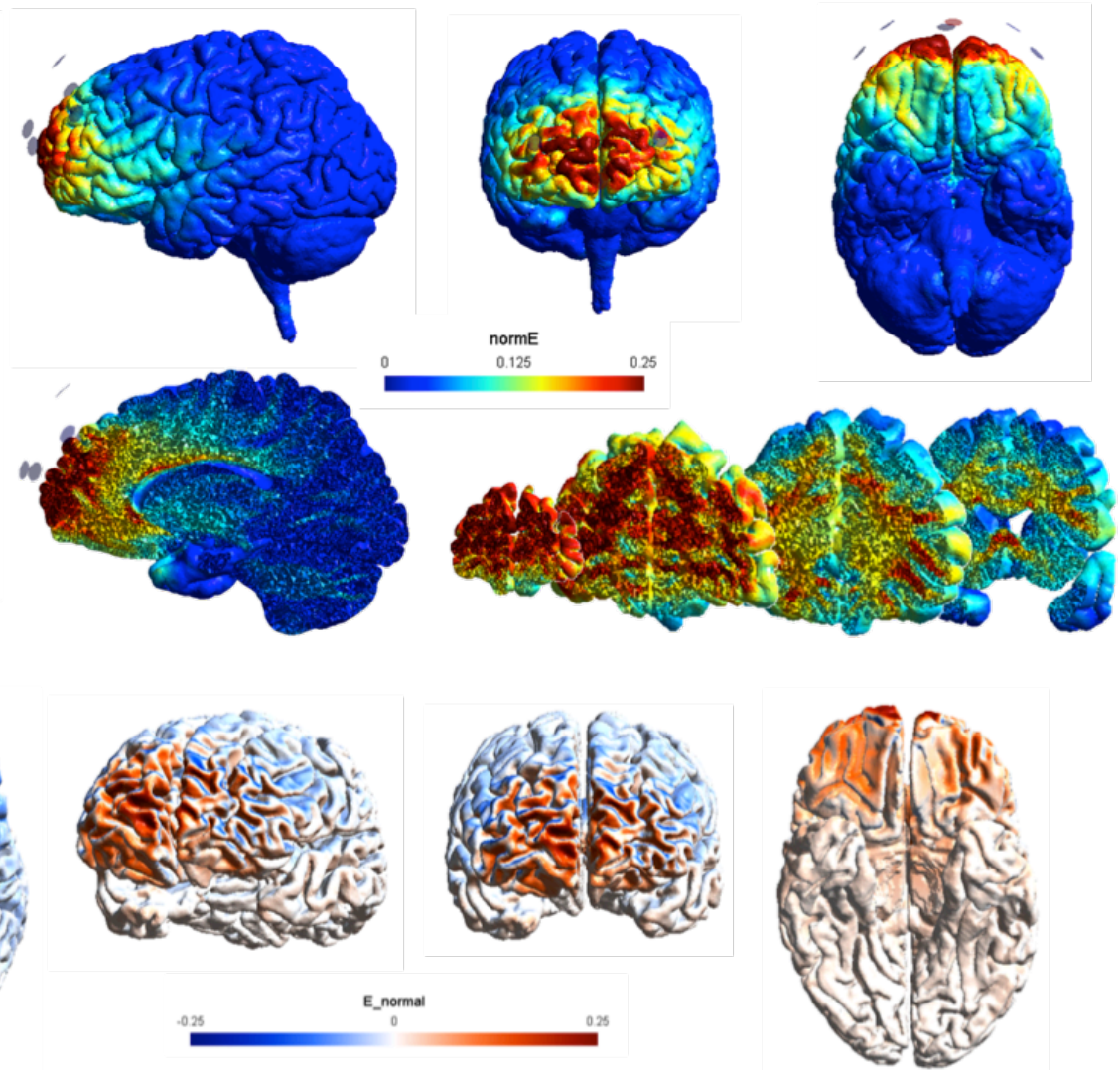

Figure 1. (A). Placement of the electrodes at 32 standard 10-20 Electroencephalography (EEG) system on the scalp with anodal high definition transcranial direct current stimulation (HDtDCS) with $6 \times 1 \mathrm{~cm}$ radius $\left(\pi \mathrm{cm}^{2}\right)$ electrodes over the Fpz $(2 \mathrm{~mA})$ and cathodal tDCS over AF3, AF4, F3, F4 and Fz (-0.4mA each). (B). Different views and slices of the map of electrical field induced by HD-tDCS montage as expressed in normE (V/m). This measure allows us to see the intensity of the stimulation independently by the polarity. (C). Views of the map of the electrical field expressed in NormalE (V/m) showing us the polarity (anodal/cathodal) of the stimulation. 


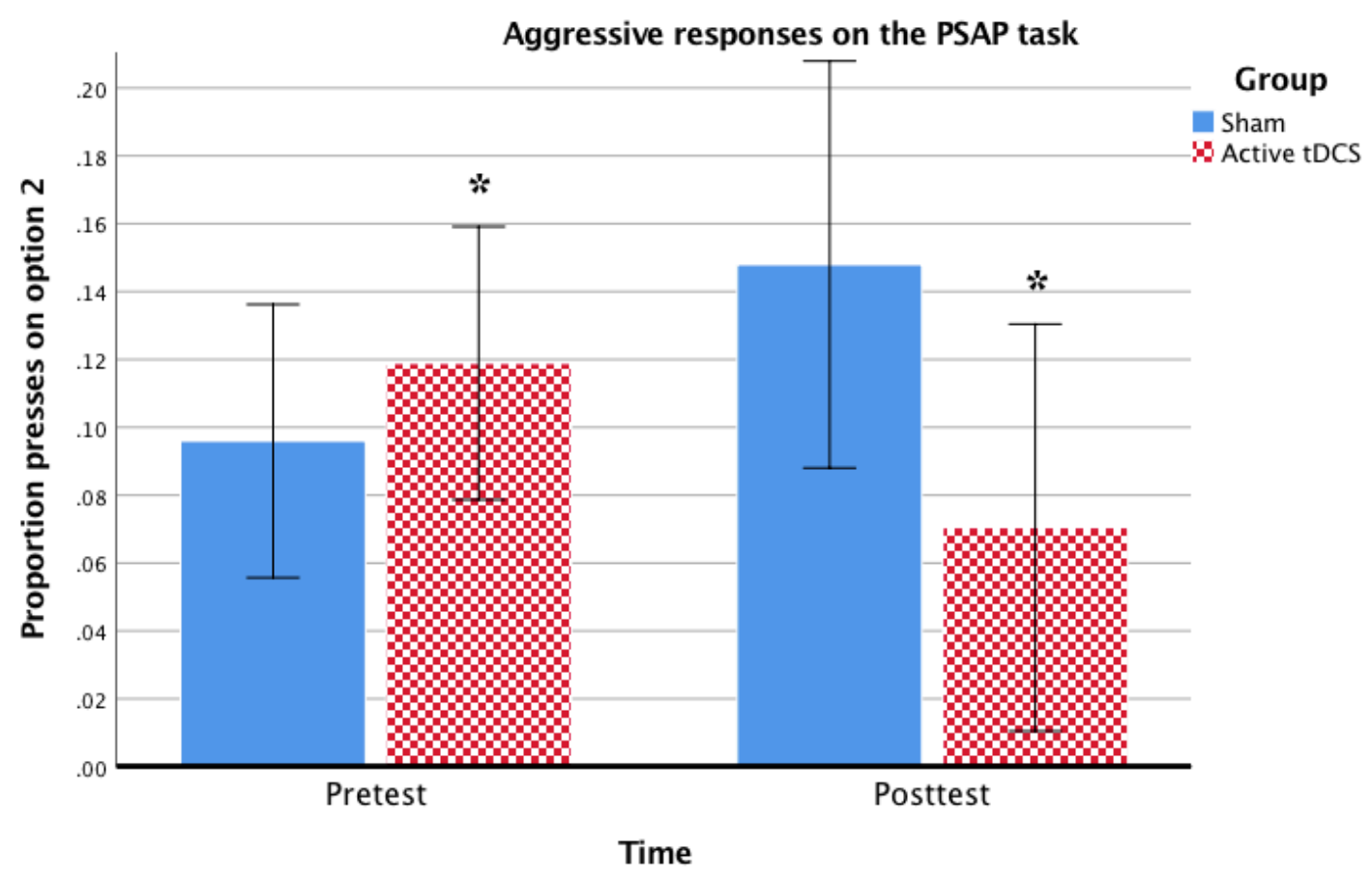

Error bars: $95 \% \mathrm{Cl}$

Figure 2. Proportion aggressive responses on the Point Subtraction Aggression Paradigm for the sham group and active tDCS group from pre to posttest. $*=$ Significant effect at $p=<.05$. 

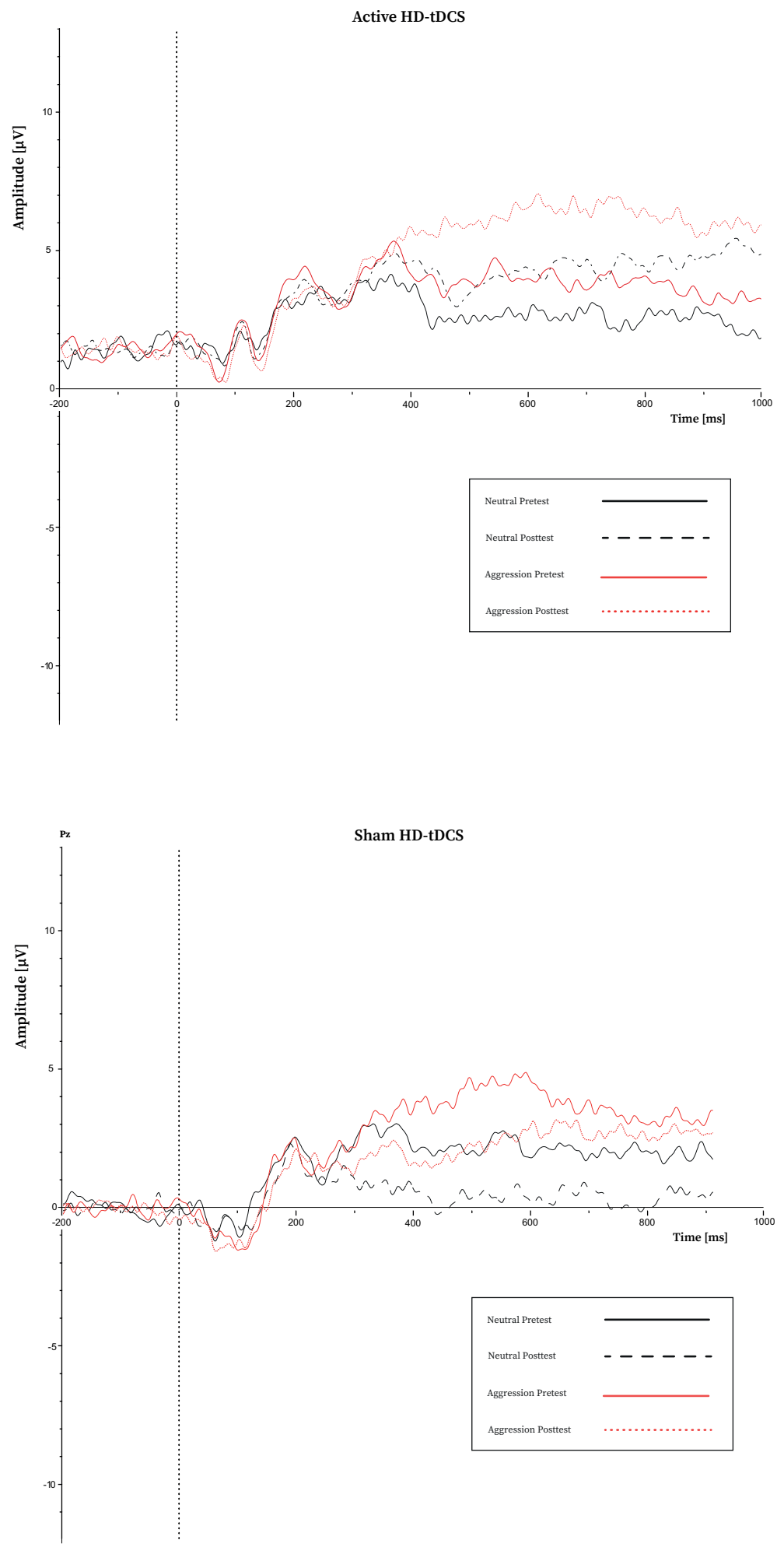

Figure 3. Event related potentials (ERPs) grand mean recorded at Pz during the passive empathy task. 


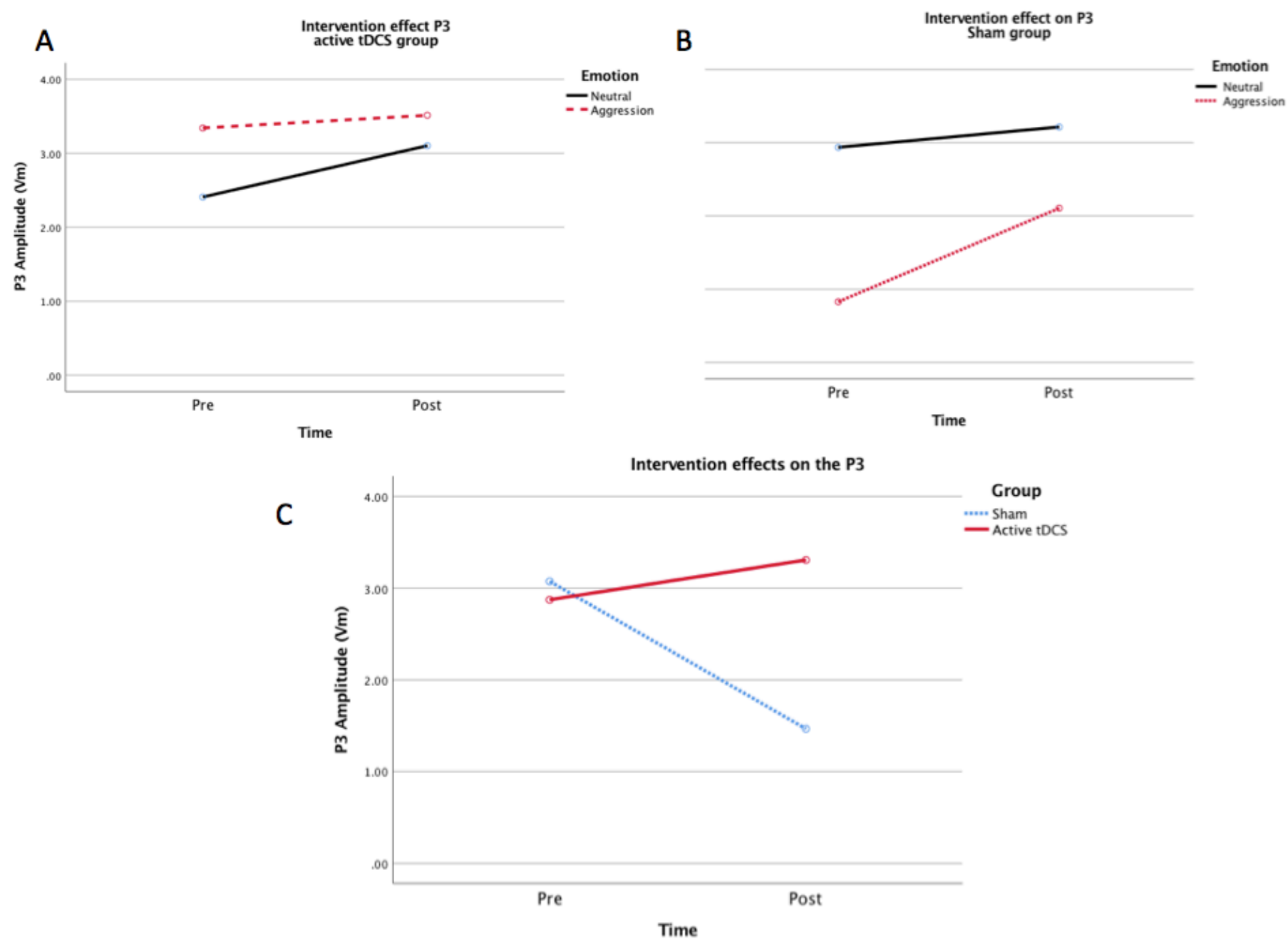

Figure 4. (A) Intervention effects on the P3 amplitude $(\mu \mathrm{V})$ for the active tDCS group on emotion from pre-to posttest (B) Intervention effects on the P3 for the Sham group on emotion from pre-to posttest (C) Intervention effects on the P3 post-hoc between the active tDCS group and the Sham group from pre-to posttest. 


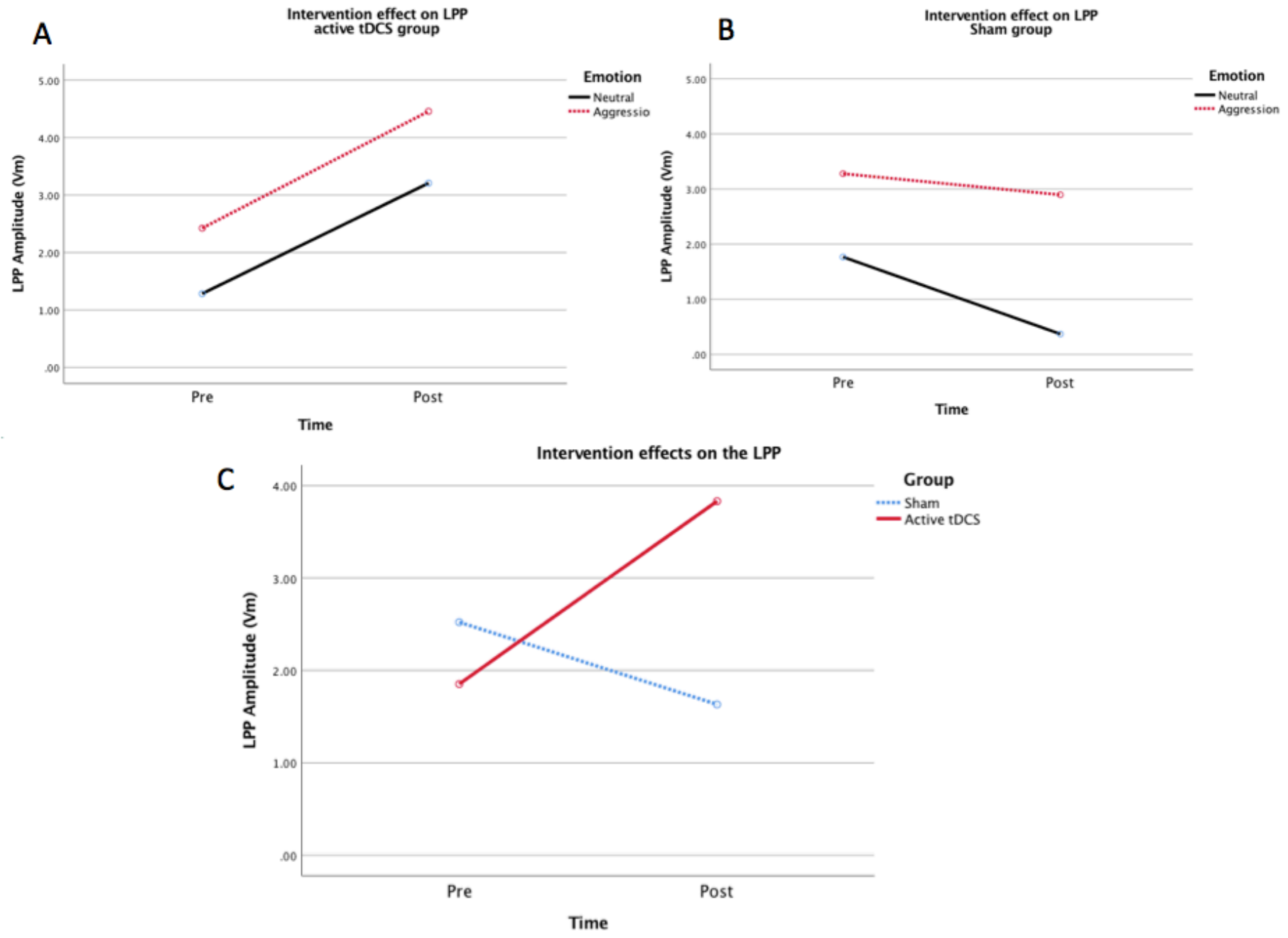

Figure 5. (A) Intervention effects on the Late Positive Potential (LPP) amplitude ( $\mu \mathrm{V})$ for the active tDCS group on emotion from pre-to posttest (B) Intervention effects on the LPP for the Sham group on emotion from pre-to posttest (C) Intervention effects on the LPP post-hoc between the active tDCS group and the Sham group from pre-to posttest. 